\title{
Different treatment efficacies and side effects of cytotoxic chemotherapy
}

\author{
Low-Jia Li ${ }^{1}$, Qingyun Chong ${ }^{2}$, Lingzhi Wang ${ }^{2,3}$, Goh Boon Cher ${ }^{1,2,3}$, Ross A. Soo ${ }^{1}$ \\ ${ }^{1}$ Department of Haematology-Oncology, National University Hospital, Singapore, Singapore; ${ }^{2}$ Cancer Science Institute of Singapore, National \\ University of Singapore, Singapore, Singapore; ${ }^{3}$ Department of Pharmacology, National University of Singapore, Singapore, Singapore \\ Contributions: (I) Conception and design: LJ Li, RA Soo; (II) Administrative support: L Wang, RA Soo; (III) Provision of study materials or patients: \\ All authors; (IV) Collection and assembly of data: All authors; (V) Data analysis and interpretation: All authors; (VI) Manuscript writing: All authors; \\ (VII) Final approval of manuscript: All authors. \\ Correspondence to: Ross A. Soo. Department of Haematology-Oncology, National University Cancer Institute, National University Health System, 1E \\ Kent Ridge Road, NUHS Tower Block Level 7, Singapore 119228, Singapore. Email: ross_soo@nuhs.edu.sg.
}

\begin{abstract}
Differences in efficacy and toxicity between Asian and Caucasian patients with lung cancer treated with systemic chemotherapy is increasingly recognised. This is a major concern in the clinical setting as it influences outcomes and affect international harmonization of drug development. Interindividual variability of pharmacokinetics, where different genetic polymorphisms affect drug metabolism, transport, and receptor binding may account for the ethnic differences. Treatment efficacy and outcomes may also be explained by differences in diet and lifestyle, access to healthcare, cultural barriers and environmental exposure. Efforts made to design prospective studies investigating ethnic specific determinants to systemic therapy and individualise lung cancer treatment based on genetic makeup of patient are important.
\end{abstract}

Keywords: Lung cancer; ethnicity; cytotoxic chemotherapy; Asian; Caucasians

Submitted Jul 31, 2019. Accepted for publication Aug 13, 2019.

doi: $10.21037 /$ jtd.2019.08.63

View this article at: http://dx.doi.org/10.21037/jtd.2019.08.63

\section{Introduction}

Worldwide, lung cancer is the most common cancer and leading cause of cancer death (1). In 2018, 2.09 million people were diagnosed with lung cancer and there were 1.76 million deaths from lung cancer. Non-small cell lung carcinoma (NSCLC), divided into two major groups by histology: squamous and non-squamous, is the most common type of lung cancer, accounting for $84 \%$ of all lung cancer diagnosis (2).

Ethnicity may be defined as a group with a common ancestry, culture or history (3). However, in our review, we refer to it as a population with a shared 'genetic ancestry'. It is now increasingly recognised that ethnicity does not just affect lung cancer epidemiology (3-10) but also the efficacy and toxicities of chemotherapeutics (11).

While tyrosine kinase inhibitors and immune checkpoint inhibitors have redefined treatment options in patients with advanced disease at presentation, the majority of patients will still require cytotoxic chemotherapy. Interindividual variability of pharmacokinetics, where different genetic polymorphisms affect drug metabolism, transport, and receptor binding may account for the ethnic differences (12-18). This is a major concern in the clinical setting as potential ethnic differences may influence outcomes and affect international harmonization of drug development. In this review paper, we will review the differences in efficacy and toxicity between Asian and Caucasian patients with lung cancer treated with systemic chemotherapy.

\section{Treatment efficacy}

\section{Small cell lung cancer}

A retrospective study of 3,428 patients from three Californian states with extensive stage small cell lung cancer 
(ED-SCLC) showed that Asian ethnicity was a favourable prognostic factor in ED-SCLC (HR $=0.785 ; \mathrm{P}=0.0076)$ (19). A potential explanation is the ethnic variability in the genetic polymorphism of drug metabolizing genes $(20,21)$.

The Japan Clinical Oncology Group (JCOG) 9511 and Southwest Oncology Group (SWOG) 0124 trial were two large phase three trials that demonstrated ethnic differences in chemotherapy response. This is despite similar eligibility criteria and treatment regimens between the two studies. The J9511 was done exclusively in Japanese patients which demonstrated a survival benefit for cisplatin/irinotecan over cisplatin/etoposide in patients with ED-SCLC. On the contrary, S0124 trial was a large North American trial that failed to confirm a survival benefit of cisplatin/irinotecan. A combined analysis of these two trials demonstrated that the response rates (RR) were higher in Japanese patients compared to United States patients, with a RR of $68 \%$ vs. $57 \%(\mathrm{P}=0.01)$ vs. $87 \%$ and $60 \%(\mathrm{P}<0.001)$ for cisplatin/ etoposide and cisplatin/irinotecan respectively. Overall survival (OS) was similar for Japanese and United States patients in the cisplatin/etoposide arm at $9.4 v s .9 .1$ months $(\mathrm{P}=0.5)$, and superior in Japanese patients in the cisplatin/ irinotecan arm at 12.8 and 9.9 months respectively $(\mathrm{P}<0.001)$ (22-24).

\section{Non-small cell lung cancer}

Several cancer registries have reported the association between survival and ethnicity in Asian patients with NSCLC. A retrospective population-based analysis of 15,185 Japanese and 13,332 Caucasians patients with NSCLC from the Japanese National Hospital Organization Study Group for Lung Cancer and Southern California Regional Cancer Registry between 1991 and 2001 revealed Japanese ethnicity to be an independent factor for OS (HR $=0.937$; 95\% CI: 0.898-0.978, P=0.0028). When analysed according to stage, Japanese patients had improved OS for stage III (HR $=0.830 ; 95 \%$ CI: $0.789-0.873, \mathrm{P}<0.0001)$ and stage IV (HR $=0.955$; 95\% CI: 0.915-0.997, $\mathrm{P}=0.0369)(25)$.

In another similar study comparing 4,622 Korean and 8,846 Caucasian patients between 1998 and 2005, Korean ethnicity was once again found to have a more favourable OS compared to Caucasians ( $\mathrm{HR}=0.869 ; \mathrm{P}<0.0001)$. The HR for OS in Korean patients compared with Caucasian patients on univariate analysis for stage I disease was 0.618 (95\% CI: $0.543-0.705$; $\mathrm{P}<0.001$ ), stage II was 0.836 (95\% CI: $0.867-1.016 ; \mathrm{P}=0.0723$ ), stage III was 0.772 (95\% CI: $0.712-0.836 ; \mathrm{P}<0.001)$ and stage IV was 0.846
(95\% CI: 0.800-0.894; $\mathrm{P}<0.001$ ). In this study, after the introduction of tyrosine kinase inhibitors in Korea in 2002, the Koreans had further improved OS advantage compared to the Caucasians $(\mathrm{HR}=0.889 ; \mathrm{P}=0.0013$ vs. $\mathrm{HR}=0.795$; $\mathrm{P}<0.0001$ in the pre and post tyrosine kinase inhibitor era respectively) (26).

Even among Asian patients living in United States, $\mathrm{Ou}$ and colleagues reported that Asian ethnicity is an independent prognostic factor regardless of smoking status. In their study of a total of 20,140 patients with NSCLC from three South California countries, Asian ethnicity has a favourable OS compared to non-Asians (HR $=0.861 ; 95 \%$ CI: 0.808-0.918, $\mathrm{P}<0.0001)$, and the highest OS among the four major ethnicities $(\mathrm{P}<0.0001)$. This remained significant even after stratification by smoking status (HR $=0.867 ; 95 \%$ CI: $0.807-0.931, \mathrm{P}<0.0001$ vs. HR $=0.841 ; 95 \%$ CI: $0.728-0.971, \mathrm{P}=0.0180$ in smokers and never smokers respectively) (27).

In 1998, SWOG established a collaboration with Japanese investigators of lung cancer. The purpose was to facilitate standardization of clinical trials and to allow for collaboration (28). With the hypothesis that ethnic related pharmacogenomics could account for differences in clinical outcomes despite similar treatment regimes, SWOG prospectively designed three phase three trialsThe Four-Arm Cooperative Study (FACS), LC00-03 and S0003 in advanced stage NSCLC, each with a common arm carboplatin/paclitaxel (29-31). In FACS, patients were randomly assigned to standard treatment in Japan (cisplatin/ irinotecan) versus experimental arms of carboplatin/ paclitaxel, cisplatin/gemcitabine, cisplatin/vinorelbine (29). In LC00-03 which was conducted in Japan, patients were assigned to carboplatin/paclitaxel versus the non-platinum regime of sequential vinorelbine/gemcitabine followed by docetaxel (30). In S0003, patients were randomly assigned to carboplatin/paclitaxel with or without the cytotoxin tirapazamine (31).

A comparative analysis of the carboplatin/paclitaxel arm shows that the patients in LC000-3 had superior progression free survival (PFS) and median survival time compared to S0003 (32). Efficacy comparisons between all three trials were also reported. RR were similar between the trial trials and ranged from $32 \%$ to $36 \%$. Median PFS was 4.5, 6 and 4 months in FACS, LC00-03 and S0003 respectively. Median survival times were numerically higher in the Japanese studies at 12 and 14 months in FACS and LC00-03 respectively compared to 9 months in S0003. One-year survival was higher at 51\% and $57 \%$ 
Table 1 Survival data, dose reductions and toxicities in FACS/LC00-03/S0003 (28-33)

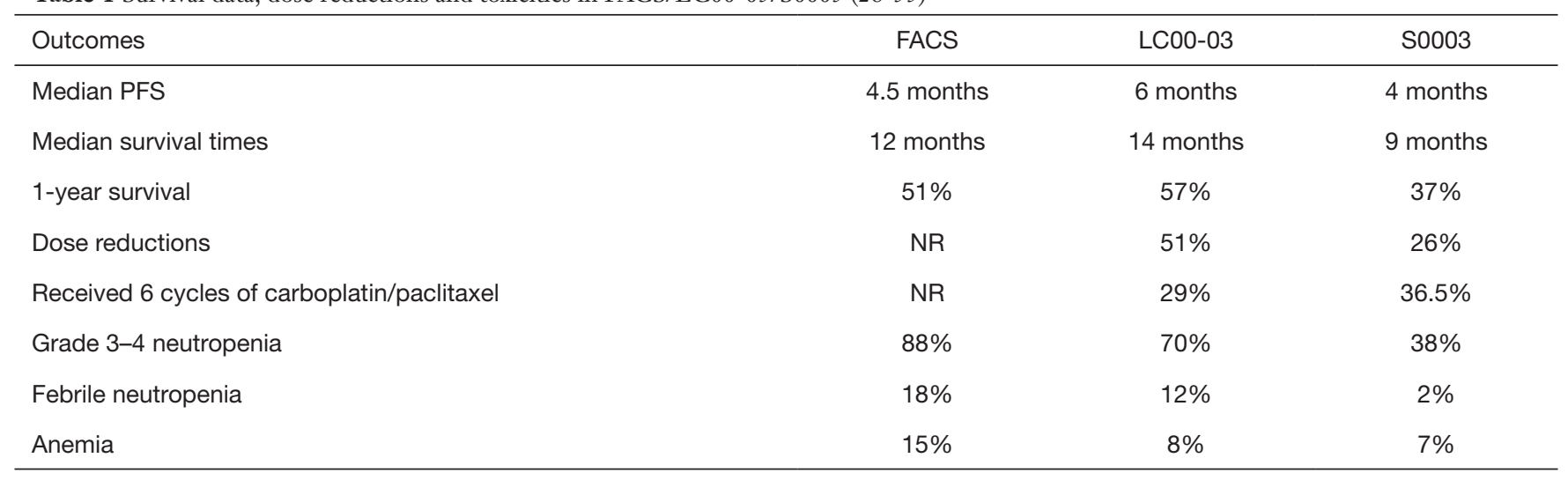

FACS, Four-Arm Cooperative Study; PFS, progression free survival; NR, not reported.

in FACS and LC00-03 respectively compared to $37 \%$ in S0003 $(\mathrm{P}=0.0004)$. This was despite numerically higher dose reductions $(51 \%$ vs. $26 \%$ in LC00-03 and $\mathrm{S} 0003$ respectively, $\mathrm{P}=0.63$ ) and more patients receiving the full six cycles of carboplatin/paclitaxel (29\% vs. 36.5\% in LC00-03 and $\mathrm{S} 0003$ respectively, $\mathrm{P}<0.0001)$. The dose reduction data from FACS was not available for comparison (28-33) (Table 1).

Genomic data was collected from patients in LC0003 and S0003 and results analysed. Genotypic associations were observed between $C Y P 3 A 4^{*} 1 B$ for PFS $(\mathrm{HR}=0.36$; 95\% CI: 0.14-0.94, P=0.04) and ERCC2 K751Q for RR (HR $=0.33 ; 95 \%$ CI: $0.13-0.83 ; \mathrm{P}=0.02)$. Notably, there was a significant difference between Japanese and US patients in genotypic distribution for $C Y P 3 A 4^{*} 1 B(\mathrm{P}=0.01)$ and ERCC2 K751Q $(\mathrm{P}=0.001)(33)$.

Docetaxel is used as a component of platinum-containing doublet regimens for previously untreated metastatic NSCLC (34). In addition, it has been approved in the second-line treatment of NSCLC (35-38). The efficacy of docetaxel across ethnic groups is likely to depend on the dosage administered, with an association between tumour $\mathrm{RR}$ and docetaxel dose. Docetaxel is approved for use at a dose of $75 \mathrm{mg} / \mathrm{m}^{2}$ as a single agent or in combination regimens, and doses ranging from $75-100 \mathrm{mg} / \mathrm{m}^{2}$ are frequently employed in global clinical trials (37-39). A lower dose of $60 \mathrm{mg} / \mathrm{m}^{2}$ docetaxel has been widely used in previous Japanese studies, as originally recommended by a Japanese phase I clinical trial due to severe haematological toxicities in Japanese patients as compared to the patients in Europe/US (40). Hence, the results from Japanese trials cannot be directly compared with global trials. Several phase I/II studies of $60 \mathrm{mg} / \mathrm{m}^{2}$ docetaxel in combination with carboplatin in Japanese NSCLC patients reported comparable RR in the range of $23-37.5 \%$, and median survival time of 12-17.6 months (41-44). These RRs observed in the Japanese studies were lower than that reported in other Asian populations.

A large phase II study performed in Singapore and Australia compared the efficacy and toxicity of carboplatin and docetaxel in different ethnic populations. Docetaxel $75 \mathrm{mg} / \mathrm{m}^{2}$ and carboplatin AUC 6 were given every 3 weeks. Caucasians and Asians made up $65 \%$ and $35 \%$ of the study population respectively. The overall RR was $42 \%$ (95\% CI: $30-54 \%)$ in the 62 evaluable patients. In a further analysis, they found that RR was significantly related to ethnicity at $65 \%$ and $31 \%$ in Asian patients and Caucasian patients respectively $(\mathrm{P}=0.01)$. A logistic regression analysis was used to determine independent predictors for response to treatment and ethnicity was found to be the only significant variable, with a odds ratio of 4.5 (95\% CI: 1.2 17.6). Ethnicity was also an independent predictor of OS $(\mathrm{P}=0.035)$. Due to significant toxicity in Asian patients who received carboplatin AUC 6 and docetaxel $75 \mathrm{mg} / \mathrm{m}^{2}$, the carboplatin dose was reduced to AUC 4.5. Despite so, RRs still favoured the Asian patients (45).

As it has been shown that docetaxel pharmacokinetics is not significantly different among ethnic populations (40), the feasibility of a higher docetaxel dose $\left(75 \mathrm{mg} / \mathrm{m}^{2}\right)$ was further evaluated in Japanese NSCLC patients. This study of docetaxel monotherapy in previously treated Japanese NSCLC patients reported an RR of $15.4 \%$ and median PFS of 4.0 months (46). In contrast, a higher RR of approximately $30 \%$ was observed in Chinese patients with unresectable NSCLC treated with $75 \mathrm{mg} / \mathrm{m}^{2}$ docetaxel in first- and second-line settings (47). A phase II study 
Table 2 Response rates and survival data in studies from Japan and Europe/UK (53)

\begin{tabular}{lcc}
\hline Regimen & Japan & Europe/UK studies \\
\hline Carboplatin/paclitaxel & 32 & $17-46$ \\
Response rate (\%) & 12.3 & $7.8-11$ \\
Median survival (months) & 51 & $32-43$ \\
1-year survival (\%) & & \\
Cisplatin/docetaxel & 37 & $17-32$ \\
Response rate (\%) & 11.3 & $7.4-11.3$ \\
Median survival (months) & 48 & $31-46$ \\
1-year survival (\%) & & \\
Cisplatin/gemcitabine & 30 & $22-42$ \\
Response rate (\%) & 14.8 & $8.1-10.9$ \\
Median survival (months) & 60 & $33-44$ \\
1-year survival (\%) & & $36-42$ \\
Cisplatin/vinorelbine & 33 & $25-39$ \\
Response rate (\%) & 11.4 & $8.1-10.1$ \\
Median survival (months) & 48 & \\
1-year survival (\%) & & \\
\hline & & \\
\hline & & \\
\hline
\end{tabular}

conducted in Singapore reported a higher RR of $50 \%$, and a 34\% RR based on intent-to-treat analysis in Asian patients with stage III inoperable NSCLC, albeit with a higher docetaxel dose of $100 \mathrm{mg} / \mathrm{m}^{2}$ every 3 weeks (48). This is comparable or higher than the reported docetaxel RRs (21-38\%) in naïve or previously treated Western patients administered with the same dose of docetaxel monotherapy (49-52). In general, docetaxel as a single agent and combination therapy have shown better efficacy in Asian than Caucasian NSCLC patients. However, Japanese trials, which used lower docetaxel dose, have generally reported lower RRs as compared to other Asian NSCLC patients.

Multiple other studies of patients with advanced NSCLC reported in Asia had a numerically longer survival. Sekine et al. retrospectively compared platinum doublet phase III trials among Japan, European and American patients with advanced NSCLC. Doses of chemotherapy were generally lower in Japanese studies and survival better. In studies of cisplatin and gemcitabine, the median survival time of 14.8 months and 1-year survival of $60 \%$ in Japanese studies were numerically higher than 8.1-10.9 months and $33-44 \%$ respectively for Europe and US studies. The OS for carboplatin/paclitaxel were 12.3 vs. 7.8-11 months, cisplatin/vinorelbine 11.4 vs. 8.1-10.1 months for Japan and Europe/US studies respectively (53) (Table 2).

Differences in outcomes between Asian and Caucasian studies were observed in a meta-analysis of randomized trials of cytotoxic chemotherapy. The OS in Asian and Caucasian patients treated with chemotherapy was 10.1 and 8.0 months $(\mathrm{P}<0.001)$ and the overall $\mathrm{RR}$ was $32 \%$ and $26 \%$ $(\mathrm{P}<0.001)$, respectively. The differences in OS remained significant in studies pre-dating the use of EGFR TKI (54).

\section{Treatment toxicities}

\section{Small cell lung cancer}

In the aforementioned J9511 and S0124 trial, enhanced hematologic toxicity was seen in Japanese patients as compared with United States patients, each receiving the exact same chemotherapy regimens. Grade 3 or more neutropenia was seen in $92 \%$ vs. $68 \%(\mathrm{P}<0.001)$, and $65 \%$ vs. $34 \%(\mathrm{P}<0.001)$ of Japanese and US patients receiving cisplatin/etoposide and cisplatin/irinotecan respectively (22-24).

Pharmacogenomic variability in single nucleotide polymorphisms (SNPs) may help explain interindividual differences and population-related differences in toxicity and outcome after chemotherapy. A pharmacogenomic analysis of S0124 showed significant associations between genotypic variants and toxicity levels. Variations of $A B C B 1$ was associated with an increased risk of irinotecan-associated grade 3 or worse diarrhoea, and UGT1A1 with increased risk of grade 3 or worse neutropenia (20,21). Multiple other studies also found pharmacogenetic information predicting for irinotecan toxicities. In one study, Fujita and Sasaki examined the effect of UGT genetic polymorphisms and found that the patients with $U G T 1 A 1 * 28$ homozygosity had a higher incidence of neutropenia compared to patients with wild-type alleles. They also found that the $U G T 1 A 1 * 6$ allele is another polymorphism associated with defective glucuronidating function and severe neutropenia and is found almost exclusively in Asian individuals with a frequency as high as $20 \%(55)$. In another study, Innocenti et al. found that a TA indel genotype (UGT1A1 variant) to be highly correlated to severe neutropenia (56). This finding was consistent with a retrospective analysis by Ando et al., in which the TA7 allele was a significant predictor of severe toxicity in patients receiving irinotecan containing regimens (57). This polymorphism is however significantly 
Table 3 Grade 3 or more toxicities in Asia and non-Asian trials (60)

\begin{tabular}{|c|c|c|c|c|}
\hline Regimen & Asian trials & Non-Asian trials & OR $(95 \% \mathrm{Cl})$ & $P$ value \\
\hline Neutropenia (\%) & 53.9 & 25.3 & $3.45(2.58-4.61)$ & $<0.001$ \\
\hline Anemia (\%) & 24.7 & 9.2 & $3.27(2.30-4.56)$ & $<0.001$ \\
\hline Thrombocytopenia (\%) & 28 & 16.0 & $2.04(1.48-2.82)$ & $<0.001$ \\
\hline \multicolumn{5}{|l|}{ Cisplatin/vinorelbine } \\
\hline Neutropenia (\%) & 78.8 & 45.6 & 4.43 (3.09-6.36) & $<0.001$ \\
\hline Anemia (\%) & 25.6 & 12.4 & $2.43(1.67-3.54)$ & $<0.001$ \\
\hline Thrombocytopenia (\%) & 2.6 & 4.5 & $0.57(0.57-1.59)$ & 0.323 \\
\hline \multicolumn{5}{|l|}{ Cisplatin/paclitaxel } \\
\hline Thrombocytopenia (\%) & 8.8 & 6.5 & 1.39 (0.94-2.06) & 0.115 \\
\hline
\end{tabular}

$\mathrm{Cl}$, confidence interval; OR, odds ratio.

more common in Caucasians than in Asians (58).

Given the strong data linking the clinical association of irinotecan toxicities and interindividual genetic differences, the Food and Drug Administration (FDA) updated the safety label for irinotecan in 2005. They included pharmacogenetic information for a dose reduction of irinotecan if a patient is homozygous for $U G T 1 A 1 * 28$ allele. Molecular assays were developed to allow rapid detection of polymorphisms, allowing treatment to be individualised (59).

\section{Non-small cell lung cancer}

In a pooled analysis of haematological toxicities in Asian and non-Asian patients from 12 phase II and 38 phase III clinical trials, severe haematological toxicities were frequently observed in Asian patients compared with non-Asians in the treatment of chemotherapy for advanced NSCLC. Grade 3 or more neutropenia and anaemia were significantly higher in Asian than non-Asian patients when treated with cisplatin/gemcitabine, cisplatin/vinorelbine and cisplatin/ paclitaxel. This difference was not observed for grade 3 or more thrombocytopenia (60) (Table 3). This differences in toxicities suggests that perhaps dose modification according to ethnicity should be considered.

Further evidence for differences in toxicities can be ascertained from the FACS, LC00-03 and S0003 trials.
While survival rates favoured the Japanese patients, the toxicity profile were more favourable for the US patients. The rates of grade 3-4 neutropenia, febrile neutropenia and anemia differed significantly in US patients but were comparable in the two Japanese studies. Rates of grade 3-4 neutropenia was $88 \%, 70 \%$ and $38 \%$, febrile neutropenia $18 \%, 12 \%$ and $2 \%$, anemia $15 \%, 8 \%$ and $7 \%$ for FACS, LC00-03 and S0003 respectively (28-33) (Table 1). Similarly, Sekine et al. also reported $88 \%$ grade 3-4 neutropenia which was numerically higher than the $14-65 \%$ reported in Europe/US studies (53).

As previously mentioned, increased susceptibility towards docetaxel toxicity is observed in Japanese as compared to Western NSCLC patients, which justified a lower dosage of docetaxel being approved for NSCLC treatment in Japan (40). Similarly, an especially high rate of docetaxel treatment-related adverse side effects was observed in the first group of Asian patients in Singapore. Neutropenia is a major toxicity of docetaxel treatment in this study, with high grade neutropenia being reported in $69 \%$ of the patients, and febrile neutropenia in approximately $30 \%$ of patients during the first cycle of treatment (48). This finding of more frequent and severe docetaxel-induced neutropenia was corroborated by a multi-centre study in Australia and Singapore (45). Specifically, a significantly higher degree of this haematological toxicity was observed in Chinese and Indians as compared to Malays despite the absence 
of docetaxel pharmacokinetics among the different ethnic groups (61). In addition, the pharmacokinetics of docetaxel and the associated haematological toxicity were reported to be comparable in Caucasian and African black patients (62).

The possible mechanisms explaining the increased incidence and severity of docetaxel toxicities in Asian patients include pharmacogenetics differences in drug transporters and metabolizing enzymes (63-65). In a study performed by our group (66), a mean docetaxel clearance rate of $15.3 \pm 4.0 \mathrm{~L} / \mathrm{h} / \mathrm{m}^{2}$ was reported which was lower than previous pharmacokinetic studies conducted in Europe and US (65). Correspondingly, neutrophil toxicity was common with a relatively high incidence of neutropenic fever at $29 \%$. The genetic polymorphisms in CYP3A5 $\left({ }^{*} 11^{*} 3\right)$ and MDR1 (C3435T) genes involved in the metabolism and membrane transport of docetaxel respectively were examined in the cohort of patients and associated with the clearance rates of docetaxel and midazolam, which is a CYP $3 A$ substrate used as a probe to predict docetaxel clearance. It was observed that the $C Y P 3 A 5^{*} 3$ allele is more common as compared to the $C Y P 3 A 5^{*} 1$ allele. Although patients with at least one $C Y P 3 A 5^{*} 1$ allele tended to exhibit higher midazolam clearance rate, there was no evident trend in the docetaxel clearance among the genotype groups, as docetaxel clearance can be affected by various factors not limited to polymorphisms in CYP $3 A 5$ gene (66).

Another study reported that the presence of both $C Y P 3 A 4^{*} 1 B$ and $C T P 3 A 5^{*} 1 A$ alleles were associated with marked increase in docetaxel clearance albeit the lack of association of individual polymorphisms in CYP $3 A 4$ and CYP3A5 on docetaxel pharmacokinetics (67). Furthermore, the $C 3435 T$ polymorphism of the MDR1 gene is known to result in the production of $\mathrm{P}$-glycoprotein with reduced membrane transporter activity, resulting in reduced clearance of its substrate like docetaxel. It was observed that $T / T$ genotype of the MDR1 gene is observed in close to $30 \%$ of the patient cohort, being especially common in Malay patients. Although the $T / T$ and $C / T$ genotypes are associated with lower midazolam and docetaxel clearance as compared to the $C / C$ genotype, the difference is not statistically significant. Nevertheless, the patient with the lowest docetaxel clearance had the $T / T$ genotype, while that with the highest docetaxel clearance had the $C / C$ genotype (66). The $C 3435 T$ polymorphism of the MDR1 gene is also found to be common in a cohort of Caucasian NSCLC patients. Nevertheless, similar to the study by our group and others, this study did not find a significant association of this polymorphism with RR and OS in NSCLC patients treated with docetaxel (68). Furthermore, SNPs in drug transporters $M D R 2$ and $S L C O 1 B 3$ were observed to be significantly associated with docetaxel-induced neutropenia in Japanese patients (69). Notably, among 28 SNPs which are significantly associated with docetaxel AUC, CYP39A1 (rs7761731) was the only SNP found to be significantly associated with high grade neutropenia in Japanese cancer patients (70). As variant alleles of these genes encoding drug transporters and metabolizing enzymes are common in specific ethnic groups, further studies of these polymorphisms in docetaxel pharmacokinetics are warranted (Table 4).

\section{Discussion}

This review articles demonstrates how interethnic and interindividual differences affect both the response and toxicities of chemotherapy. Identifying genetic variants has the potential to favourably impact cancer care. However, there are challenges involved in studying the pharmacoethnicity of cancer therapies. Firstly, understanding the underlying genetic mechanism of these differences often requires a diverse population with large trials and international collaboration. There are also often more than one gene affecting chemotherapy outcomes and toxicities, uncommon but potentially important polymorphisms and lastly, chemotherapy cannot be administered in healthy subjects (74).

Despite these limitations, the identification of the UGT $1 A 1 * 28$ allele in irinotecan metabolism is a successful and encouraging example of how these efforts can potentially translate into clinical practice and better outcomes for our patients. The FACS, LC00-03, and S0003 with a common arm of carboplatin and paclitaxel is also another feasible way of comparing pharmacogenomic results and evaluate population related differences in chemotherapy in a setting where joint clinical trials sponsored by the US National Cancer Institute were not possible.

Other than ethnic differences, treatment efficacy and outcomes are also explained by differences in diet and lifestyle, access to healthcare, cultural barriers and environmental exposure to carcinogens and pathogens (75). In the 1980 s, about $70 \%$ of lung cancers occurs in the developed world. With the decline of tobacco use in the Western countries, the burden of lung cancer is shifting to the developing world with at least $50 \%$ of all lung cancers now occurring in the developing world (76). Another study demonstrated how black patients with early stage NSCLC 
Table 4 SNPs and effect on Docetaxel metabolism

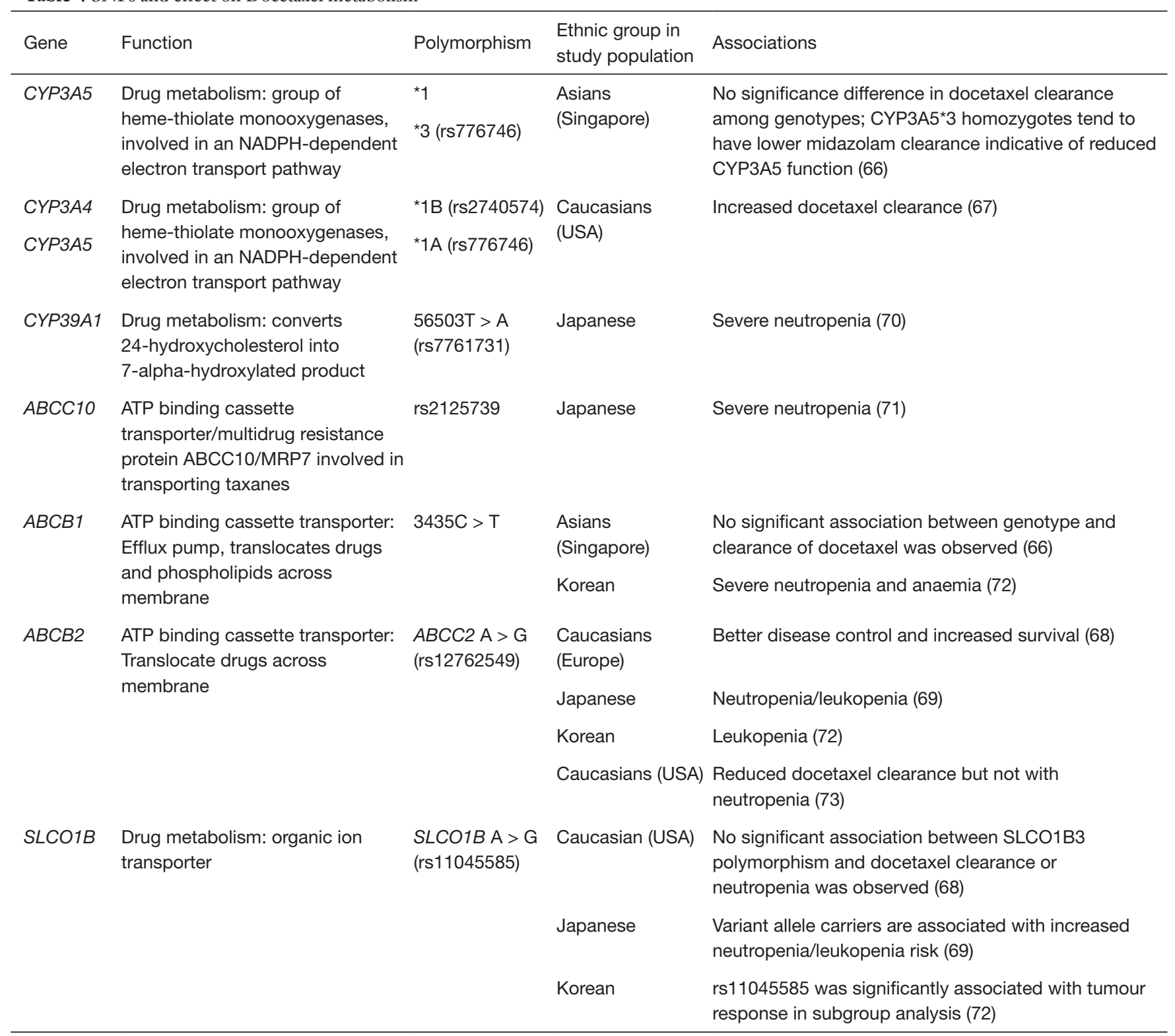

have worse OS than white patients in the US. Firstly, black patients had significantly less invasive staging than white patients $(\mathrm{OR}=0.75$; 95\% CI: 0.67-0.83). Even when they had invasive staging, they were also far less likely than their white counterparts to have potentially curable surgery (OR $=0.55 ; 95 \%$ CI, 0.47-0.64) (77). This study reflects how even in the same country, there is an ethnic difference in the willingness and ability of a patient to undergo treatment which affected outcomes. However, genetics still play an important role. For example, we previously discussed how
Asians had more favourable RRs and OS compared to the Australians receiving the same treatment of carboplatin/ docetaxel (45).

\section{Conclusions}

Ethnicity differences in treatment efficacy and toxicities exists in patients treated with chemotherapy. There are potential differences in trial designs, patient demographics and pharmacogenomics. Genomic diversity across racial 
and ethnic groups pose unique but important challenges for therapeutic opportunities and personalised medicine. It is important to appreciate inter-ethnic differences in drug disposition as data is often extrapolated from landmark studies done in western countries to Asian populations for clinical use. Efforts made to individualise lung cancer treatment based on genetic makeup of patient is important in providing personalised care for patients.

\section{Acknowledgments}

Funding: None.

\section{Footnote}

Provenance and Peer Review: This article was commissioned by the Guest Editors (Tomoya Kawaguchi and Phillip C. Mack) for the Series "Ethnic Difference in Lung Cancer" published in Fournal of Thoracic Disease. The article was sent for external peer review organized by the Guest Editors and the editorial office.

Conflicts of Interest: All authors have completed the ICMJE uniform disclosure form (available at http://dx.doi. org/10.21037/jtd.2019.08.63). The series "Ethnic Difference in Lung Cancer" was commissioned by the editorial office without any funding or sponsorship. GBC reports grants from National Medical Research Council, Singapore, grants from Biomedical Research Council, Singapore, grants from Ministry of Education, Singapore, grants from MSD, other from Bayer Healthcare, personal fees from MSD, outside the submitted work; In addition, Dr. Goh has a patent Detection of Biomarkers For Non-Small Cell Lung Cancer pending. RAS reports grants and personal fees from AstraZeneca, personal fees from BMS, grants and personal fees from Boehringer Ingelheim, personal fees from Lilly, personal fees from MSD, personal fees from Novartis, personal fees from Pfizer, personal fees from Roche, personal fees from Taiho, personal fees from Takeda, personal fees from Yuhan, during the conduct of the study. The authors have no other conflicts of interest to declare.

Ethical Statement: The authors are accountable for all aspects of the work in ensuring that questions related to the accuracy or integrity of any part of the work are appropriately investigated and resolved.

Open Access Statement: This is an Open Access article distributed in accordance with the Creative Commons Attribution-NonCommercial-NoDerivs 4.0 International License (CC BY-NC-ND 4.0), which permits the noncommercial replication and distribution of the article with the strict proviso that no changes or edits are made and the original work is properly cited (including links to both the formal publication through the relevant DOI and the license). See: https://creativecommons.org/licenses/by-nc-nd/4.0/.

\section{References}

1. World Health Organization. Cancer. Available online: https://www.who.int/news-room/fact-sheets/detail/cancer. (2018, accessed 4 May 2019).

2. Cancer.Net. Lung Cancer - Non-Small Cell: Statistics. Available online: https://www.cancer.net/cancer-types/ lung-cancer-non-small-cell/statistics. (2019, accessed 4 May 2019).

3. Jiménez TR. Affiliative ethnic identity: a more elastic link between ethnic ancestry and culture. Ethn Racial Stud 2010;33:1756-75.

4. Epplein M, Schwartz SM, Potter JD, et al. Smokingadjusted lung cancer incidence among Asian-Americans (United States). Cancer Causes Control 2005;16:1085-90.

5. Lim WY, Tan CS, Loy EY, et al. Lung cancer incidence in Singapore: ethnic and gender differences. Lung Cancer 2014;84:23-30.

6. Chan WC, Colbourne MJ, Fung SC, et al. Bronchial cancer in Hong Kong 1976-1977. Br J Cancer 1979;39:182-92.

7. Hinds MW, Stemmermann GN, Yang HY, et al. Differences in lung cancer risk from smoking among Japanese, Chinese, and Hawaiian women in Hawaii. Int J Cancer 1981;27:297-302.

8. Gao YT, Blot WJ, Zheng W, et al. Lung cancer among Chinese women. Int J Cancer 1987;40:604-9.

9. Le Marchand L, Wilkens LR, Kolonel LN. Ethnic differences in the lung cancer risk associated with smoking. Cancer Epidemiol Biomarkers Prev 1992;1:103-7.

10. Cetin K, Ettinger DS, Hei YJ, et al. Survival by histologic subtype in stage IV nonsmall cell lung cancer based on data from the Surveillance, Epidemiology and End Results Program. Clin Epidemiol 2011;3:139-48.

11. Soo RA, Kawaguchi T, Loh M, et al. Differences in outcome and toxicity between Asian and caucasian patients with lung cancer treated with systemic therapy. Future Oncol 2012;8:451-62.

12. Wood AJ. Ethnic differences in drug disposition and 
response. Ther Drug Monit 1998;20:525-6.

13. Kalow W. Ethnic differences in drug metabolism. Clin Pharmacokinet 1982;7:373-400.

14. Weber WW. Populations and genetic polymorphisms. Mol Diagn 1999;4:299-307.

15. Bertilsson L. Geographic/interracial differences in polymorphic drug oxidation. Clin Pharmacokinet 1995;29:192-209.

16. Andersson T, Regardh CG, Lou YC, et al. Polymorphic hydroxylation of S-mephenytoin and omeprazole metabolism in Caucasians and Chinese subjects. Pharmacogenetics 1992;2:25-31.

17. Bertilsson L, Lou YQ, Du YL, et al. Pronounced differences between native Chinese and Swedish populations of debrisoquin and S-mephenytoin. Clin Pharmacol Ther 1992;51:388-97.

18. Lin HJ, Han CY, Lin BK, et al: Ethnic distribution of slow acetylator mutations in the polymorphic $\mathrm{N}$-acetyltransferase (NAT2) gene. Pharmacogenetics 1994:4:125-34.

19. Ou SH, Ziogas A, Zell JA. Prognostic factors for survival in extensive stage small cell lung cancer (ED-SCLC): the importance of smoking history, socioeconomic and marital statuses, and ethnicity. J Thorac Oncol 2009;4:37-43.

20. Lara PN Jr, Natale R, Crowley J, et al. Phase III trial of irinotecan/cisplatin compared with etoposide/cisplatin in extensive-stage small-cell lung cancer: clinical and pharmacogenomic results from SWOG S0124. J Clin Oncol 2009;27:2530-5.

21. Lara P, Redman M, Lenz H, et al. Cisplatin (Cis)/etoposide (VP16) compared to cis/irinotecan (CPT11) in extensivestage small cell lung cancer (E-SCLC): Pharmacogenomic (PG) and comparative toxicity analysis of JCOG 9511 and SWOG 0124. J Clin Orthod 2007;25:7524.

22. Fisher MD, D'Orazio A. Irinotecan and cisplatin versus etoposide and cisplatin in small-cell lung cancer: JCOG 9511. Clin Lung Cancer 2000;2:23-4.

23. Natale RB, Lara PN, Chansky K, et al. S0124: A randomized phase III trial comparing irinotecan/cisplatin (IP) with etoposide/cisplatin (EP) in patients (pts) with previously untreated extensive stage small cell lung cancer (E-SCLC). J Clin Oncol 2008;26:7512.

24. Lara PN Jr, Chansky K, Shibata T, et al. Common arm comparative outcomes analysis of phase 3 trials of cisplatin + irinotecan versus cisplatin + etoposide in extensive stage small cell lung cancer: final patient-level results from Japan Clinical Oncology Group 9511 and Southwest Oncology Group 0124. Cancer 2010;116:5710-5.
25. Kawaguchi T, Matsumura A, Fukai S, et al. Japanese ethnicity compared with Caucasian ethnicity and neversmoking status are independent favorable prognostic factors for overall survival in non-small cell lung cancer: a collaborative epidemiologic study of the National Hospital Organization Study Group for Lung Cancer (NHSGLC) in Japan and a Southern California Regional Cancer Registry databases. J Thorac Oncol 2010;5:1001-10.

26. Ahn MJ, Lee J, Park YH, et al. Korean ethnicity as compared with white ethnicity is an independent favorable prognostic factor for overall survival in non-small cell lung cancer before and after the oral epidermal growth factor receptor tyrosine kinase inhibitor era. J Thorac Oncol 2010;5:1185-96.

27. Ou SH, Ziogas A, Zell JA. Asian ethnicity is a favorable prognostic factor for overall survival in non-small cell lung cancer (NSCLC) and is independent of smoking status. J Thorac Oncol 2009;4:1083-93.

28. Leigh BR, Gandara DR, Crowley JJ, et al. Summary of the proceedings of the United States--Japan lung cancer clinical trials summit: San Francisco, CA, 20-22 November, 1998. Lung Cancer 1999;24:181-91.

29. Ohe Y, Ohashi Y, Kubota K, et al. Randomized phase III study of cisplatin plus irinotecan versus carboplatin plus paclitaxel, cisplatin plus gemcitabine, and cisplatin plus vinorelbine for advanced non-small-cell lung cancer: Four-Arm Cooperative Study in Japan. Ann Oncol 2007; 18:317-23.

30. Kubota K, Kawahara M, Ogawara M, et al. Vinorelbine plus gemcitabine followed by docetaxel versus carboplatin plus paclitaxel in patients with advanced non-small-cell lung cancer: a randomised, open-label, phase III study. Lancet Oncol 2008;9:1135-42.

31. Williamson SK, Crowley JJ, Lara PN Jr, et al. Phase III trial of paclitaxel plus carboplatin with or without tirapazamine in advanced non-small-cell lung cancer: Southwest Oncology Group Trial S0003. J Clin Oncol 2005;23:9097-104.

32. Gandara DR, Ohe Y, Kubota K, et al. Japan-SWOG common arm analysis of paclitaxel/carboplatin in advanced stage non-small cell lung cancer (NSCLC): A model for prospective comparison of cooperative group trials. J Clin Oncol 2004;22:7007.

33. Gandara DR, Kawaguchi T, Crowley J, et al. JapaneseUS common-arm analysis of paclitaxel plus carboplatin in advanced non-small-cell lung cancer: a model for assessing population-related pharmacogenomics. J Clin Oncol 2009;27:3540-6. 
34. Hardin C, Shum E, Singh AP, et al. Emerging treatment using tubulin inhibitors in advanced non-small cell lung cancer. Expert Opin Pharmacother 2017;18:701-16.

35. Garon EB, Ciuleanu TE, Arrieta O, et al. Ramucirumab plus docetaxel versus placebo plus docetaxel for secondline treatment of stage IV non-small-cell lung cancer after disease progression on platinum-based therapy (REVEL): a multicentre, double-blind, randomised phase 3 trial. Lancet 2014;384:665-73.

36. Reck M, Kaiser R, Mellemgaard A, et al. Docetaxel plus nintedanib versus docetaxel plus placebo in patients with previously treated non-small-cell lung cancer (LUMELung 1): a phase 3, double-blind, randomised controlled trial. Lancet Oncol 2014;15:143-55.

37. Fossella FV. Docetaxel in second-line treatment of nonsmall-cell lung cancer. Clin Lung Cancer 2002;3 Suppl 2:S23-8.

38. Fossella FV, DeVore R, Kerr RN, et al. Randomized phase III trial of docetaxel versus vinorelbine or ifosfamide in patients with advanced non-small-cell lung cancer previously treated with platinum-containing chemotherapy regimens. The TAX 320 Non-Small Cell Lung Cancer Study Group. J Clin Oncol 2000;18:2354-62.

39. Fossella F, Pereira JR, von Pawel J, et al. Randomized, multinational, phase III study of docetaxel plus platinum combinations versus vinorelbine plus cisplatin for advanced non-small-cell lung cancer: the TAX 326 study group. J Clin Oncol 2003;21:3016-24.

40. Kenmotsu H, Tanigawara Y. Pharmacokinetics, dynamics and toxicity of docetaxel: Why the Japanese dose differs from the Western dose. Cancer Sci 2015;106:497-504.

41. Kawahara M, Atagi S, Komuta K, et al. Carboplatin plus either docetaxel or paclitaxel for Japanese patients with advanced non-small cell lung cancer. Anticancer Res 2013;33:4631-7.

42. Kasahara K, Kimura H, Shibata K, et al. A phase II study of combination chemotherapy with docetaxel and carboplatin for patients with advanced or metastatic nonsmall cell lung cancer. Anticancer Res 2006;26:3723-8.

43. Kataoka K, Suzuki R, Taniguchi H, et al. Phase I/II trial of docetaxel and carboplatin as a first-line therapy in patients with stage IV non-small-cell lung cancer. Lung 2006;184:133-9.

44. Kunitoh H, Watanabe K, Onoshi T, et al. Phase II trial of docetaxel in previously untreated advanced non-small-cell lung cancer: a Japanese cooperative study. J Clin Oncol 1996;14:1649-55.

45. Millward MJ, Boyer MJ, Lehnert M, et al. Docetaxel and carboplatin is an active regimen in advanced non-smallcell lung cancer: a phase II study in Caucasian and Asian patients. Ann Oncol 2003;14:449-54.

46. Yamada K, Takeoka H, Mizoguchi Y, et al. Feasibility reevaluation of $75 \mathrm{mg} / \mathrm{m}(2)$ docetaxel in Japanese patients with previously treated non-small cell lung cancer. Jpn J Clin Oncol 2014;44:338-45.

47. Perng RP, Shih JF, Chen YM, et al. A phase II study of single-agent docetaxel chemotherapy for non-small cell lung cancer. Jpn J Clin Oncol 2000;30:429-34.

48. Goh BC, Lehnert M, Lim HL, et al. Phase II trial of docetaxel in Asian patients with inoperable stage III nonsmall cell lung cancer. Acta Oncol 2000;39:225-9.

49. Cerny T, Kaplan S, Pavlidis N, et al. Docetaxel (Taxotere) is active in non-small-cell lung cancer: a phase II trial of the EORTC Early Clinical Trials Group (ECTG). Br J Cancer 1994;70:384-7.

50. Fossella FV, Lee JS, Murphy WK, et al. Phase II study of docetaxel for recurrent or metastatic non-small-cell lung cancer. J Clin Oncol 1994;12:1238-44.

51. Francis PA, Rigas JR, Kris MG, et al. Phase II trial of docetaxel in patients with stage III and IV non-small-cell lung cancer. J Clin Oncol 1994;12:1232-7.

52. Rigas JR. Docetaxel in stage III and IV non-small cell lung cancer. Eur J Cancer 1995;31A Suppl 4:S18-20.

53. Sekine I, Nokihara H, Yamamoto N, et al. Common arm analysis: one approach to develop the basis for global standardization in clinical trials of non-small cell lung cancer. Lung Cancer 2006;53:157-64.

54. Soo RA, Loh M, Mok TS, et al. Ethnic differences in survival outcome in patients with advanced stage non-small cell lung cancer: results of a meta-analysis of randomized controlled trials. J Thorac Oncol 2011;6:1030-8.

55. Fujita K, Ando Y, Nagashima F, et al. Genetic linkage of UGT1A7 and UGT1A9 polymorphisms to UGT1A1*6 is associated with reduced activity for SN-38 in Japanese patients with cancer. Cancer Chemother Pharmacol 2007;60:515-22.

56. Innocenti F, Undevia SD, Iyer L, et al. Genetic variants in the UDP-glucuronosyltransferase $1 \mathrm{~A} 1$ gene predict the risk of severe neutropenia of irinotecan. J Clin Oncol 2004;22:1382-8.

57. Ando Y, Saka H, Ando M, et al. Polymorphisms of UDPglucuronosyltransferase gene and irinotecan toxicity: A pharmacogenetic analysis. Cancer Res 2000;60:6921-6.

58. Liu JY, Qu K, Sferruzza AD, et al. Distribution of the UGT1A1*28 polymorphism in Caucasian and Asian populations in the US: a genomic analysis of 138 healthy 
individuals. Anticancer Drugs 2007;18:693-6.

59. Hasegawa Y, Ando Y, Shimokata K. Screening for adverse reactions to irinotecan treatment using the Invader UGT1A1 Molecular Assay. Expert Rev Mol Diagn 2006;6:527-33.

60. Hasegawa Y, Kawaguchi T, Kubo A, et al. Ethnic difference in hematological toxicity in patients with nonsmall cell lung cancer treated with chemotherapy: a pooled analysis on Asian versus non-Asian in phase II and III clinical trials. J Thorac Oncol 2011;6:1881-8.

61. Hor SY, Lee SC, Wong CI, et al. PXR, CAR and HNF4alpha genotypes and their association with pharmacokinetics and pharmacodynamics of docetaxel and doxorubicin in Asian patients. Pharmacogenomics J 2008;8:139-46.

62. Lewis LD, Miller AA, Rosner GL, et al. A comparison of the pharmacokinetics and pharmacodynamics of docetaxel between African-American and Caucasian cancer patients: CALGB 9871. Clin Cancer Res 2007;13:3302-11.

63. Fukae M, Shiraishi Y, Hirota T, et al. Population pharmacokinetic-pharmacodynamic modeling and modelbased prediction of docetaxel-induced neutropenia in Japanese patients with non-small cell lung cancer. Cancer Chemother Pharmacol 2016;78:1013-23.

64. Yano R, Konno A, Watanabe K, et al. Pharmacoethnicity of docetaxel-induced severe neutropenia: integrated analysis of published phase II and III trials. Int J Clin Oncol 2013;18:96-104.

65. Clarke SJ, Rivory LP. Clinical pharmacokinetics of docetaxel. Clin Pharmacokinet 1999;36:99-114.

66. Goh BC, Lee SC, Wang LZ, et al. Explaining interindividual variability of docetaxel pharmacokinetics and pharmacodynamics in Asians through phenotyping and genotyping strategies. J Clin Oncol 2002;20:3683-90.

67. Baker SD, Verweij J, Cusatis GA, et al. Pharmacogenetic pathway analysis of docetaxel elimination. Clin Pharmacol Ther 2009;85:155-63.

Cite this article as: Li LJ, Chong Q, Wang L, Cher GB, Soo RA. Different treatment efficacies and side effects of cytotoxic chemotherapy. J Thorac Dis 2020;12(7):3785-3795. doi: $10.21037 /$ jtd.2019.08.63
68. Szczyrek M, Mlak R, Krawczyk P, et al. Polymorphisms of Genes Encoding Multidrug Resistance Proteins as a Predictive Factor for Second-Line Docetaxel Therapy in Advanced Non-small Cell Lung Cancer. Pathol Oncol Res 2017;23:607-14.

69. Kiyotani K, Mushiroda T, Kubo M, et al. Association of genetic polymorphisms in SLCO1B3 and ABCC2 with docetaxel-induced leukopenia. Cancer Sci 2008;99:967-72.

70. Uchiyama T, Kanno H, Ishitani K, et al. An SNP in CYP39A1 is associated with severe neutropenia induced by docetaxel. Cancer Chemother Pharmacol 2012;69:1617-24

71. Sone K, Oguri T, Uemura T, et al. Genetic variation in the ATP binding cassette transporter ABCC10 is associated with neutropenia for docetaxel in Japanese lung cancer patients cohort. BMC Cancer 2019;19:246.

72. Choi JR, Kim JO, Kang DR, et al. Genetic Variations of Drug Transporters Can Influence on Drug Response in Patients Treated with Docetaxel Chemotherapy. Cancer Res Treat 2015;47:509-17.

73. Lewis LD, Miller AA, Owzar K, et al. The relationship of polymorphisms in ABCC2 and SLCO1B3 with docetaxel pharmacokinetics and neutropenia: CALGB 60805 (Alliance). Pharmacogenet Genomics 2013;23:29-33.

74. O'Donnell PH, Dolan ME. Cancer pharmacoethnicity: ethnic differences in susceptibility to the effects of chemotherapy. Clin Cancer Res 2009;15:4806-14.

75. Wallace TA, Martin DN, Ambs S. Interactions among genes, tumor biology and the environment in cancer health disparities: examining the evidence on a national and global scale. Carcinogenesis 2011;32:1107-21.

76. Thun MJ, DeLancey JO, Center MM, et al. The global burden of cancer: priorities for prevention. Carcinogenesis 2010;31:100-10.

77. Lathan CS, Neville BA, Earle CC. The effect of race on invasive staging and surgery in non-small-cell lung cancer. J Clin Oncol 2006;24:413-8. 